\title{
Incorporating services for common mental disorders and substance use disorders for people living with HIV along the HIV treatment cascade
}

\author{
Thomas F. Kresina ${ }^{1 *}$, Ilana F. Lapidos-Salaiz ${ }^{2}$, Elizabeth Lopez ${ }^{1}$ and Kimberly Johnson ${ }^{1}$ \\ ${ }^{1}$ Center for Substance Abuse Treatment, Substance Abuse and Mental Health Services Administration, Rockville, Maryland, USA \\ ${ }^{2}$ Office of HIV/AIDS, USAID, Washington, DC, USA
}

\begin{abstract}
The prevalence of common mental disorders (CMDs) and substance use disorders (SUDs) are higher in people living with HIV (PLHIV) than in the general population. Numerous studies have shown the high negative impact of these disorders on HIV clinical outcomes for PLHIV and the continued lack of services for CMDs and SUDs in HIV care and treatment programs, particularly in resource limited settings. The provision of services for CMDs/SUDs along the HIV care and treatment continuum provides a platform for better clinical outcomes that can substantially impact HIV epidemic control. Development and analysis of the HIV treatment cascade (number of PLHIV, number of diagnosed PLHIV, number PLHIV receiving antiretroviral treatment (ART), and number of PLHIV with suppressed viral load) for PLHIV with CMDs and SUDs can provide important data on the efficacy and impact of the services for CMDs and SUDs, as well as, reveal gaps in care and services. Integration or co-location into HIV primary care of effective evidence-based services for CMDs and SUDs provide the best platform for addressing both CMDs/SUDs and HIV infection for PLHIV.
\end{abstract}

\section{Introduction}

The World Health Organization (WHO) defines mental health as a fundamental component of personal health and well-being [1]. CMDs, as classified by the Diagnostic and Statistical Manual of Mental Disorders (DSM-5) [2] or by the International Classification of Diseases and Related Health Problems (ICD-10) [3], result in both disproportionately higher rates of disability and mortality, and account for up to $10 \%$ of the global burden of disease [4]. In addition, CMD occur in a higher prevalence in PLHIV, but remain under-diagnosed and poorly treated, particularly in low and middle income countries [5]. Globally, as reviewed in [6], the prevalence of CMDs occurring in PLHIV range from $20-35 \%$ for depression, $19-37 \%$ for anxiety disorders, $15-26 \%$ for post-traumatic stress disorders and $5-23 \%$ for severe mental illnesses. In addition, SUDs have been reported among $7-16 \%$ of PLHIV, all of which impact the care and treatment of HIV infection along the treatment cascade [6].

Common Mental Disorders and HIV Infection in Low and Middle Income Countries

When population based screening occurs, CMDs can be identified at higher rates in PLHIV compared to the general population [79]. WHO guidelines underscore that PLHIV in resource-limited settings may experience CMDs, and that HIV care settings provide the opportunity to screen for and manage common CMDs through a range of care and treatment options that include counseling and pharmacotherapy $[9,10]$

Depression and anxiety are common CMDs observed among PLHIV, particularly women [11-15]. Screening studies in African countries have reported the prevalence of depression in PLHIV ranging from $8-28 \%$ [14,16-19]. For anxiety disorders, screening studies have shown up to 5-fold increase in prevalence in PLHIV compared to the general population [19-21]. In low and middle income countries, female sex, older age, low education, low income, HIV infection, HIV stigma, and poverty are strongly associated with CMDs [22-26]. Other CMDs, that occur in higher prevalence in PLHIV than the general population are suicide and suicide ideation. Recent studies have reported suicide rates of $12-20 \%$ and suicide ideation in roughly one in three PLHIV [27-29]. Risk factors for suicide attempts were marital status, HIV stigma, poor disease management and poor social support, while factors associated with suicide ideation were noted to be female sex, depression/anxiety, marital status, learning their HIV status and poor disease management. WHO recommends addressing psychological distress, the societal risk factors for suicide, augmenting protective factors, and ongoing monitoring of PLHIV as part of a comprehensive suicide prevention strategy. In addition, the use of the antidepressant, Amitriptyline, is recommended in low and middle income countries because of costs and availability to reduce the symptoms of depression (a precursor to suicide) as a component of care, specifically when emergency or rapid onset of action is required $[9,10,30]$.

Substance Use Disorders and HIV Infection in Low and Middle Income Countries

Correspondence to: Thomas F. Kresina, PhD, Division of Pharmacologic Therapies, Center for Substance Abuse Treatment, Substance Abuse and Mental Health Services Administration, 5600 Parklawn Drive, Rockville, MD USA 20857; E-mail: tkresina@samhsa.gov

Key words: mental health, common mental disorders, HIV treatment cascade, depression, anxiety, suicide ideation, substance use disorders, alcohol use disorder, health services integration, retention in care, cost-effectiveness

Received: April 22, 2017; Accepted: May 15, 2017; Published: May 19, 2017 
People who use drugs are at elevated risk for both SUDs and HIV infection. In the context of HIV infection, PLHIV who acquire a SUD are frequently disengaged from the healthcare system, thereby limiting their access to HIV services [31]. Creating an enabling care environment for people who use drugs, in a primary care setting, and co-locating treatment for SUDs and HIV infection is an evidencebased best practice that improves patient treatment service acquisition and outcomes $[32,33]$. In addition, integrating HIV and drug treatment services promotes the reengagement of people who use drugs who are lost to follow-up through the reduction of barriers to access care and treatment $[33,34]$. With integrated services, PLHIV can be screened for alcohol and drug use allowing for on-site services addressing harmful alcohol use and stimulant use which can enhance HIV transmission risk through sexual transmission or injection transmission [35-38]. Thus, alcohol-, opioid- and stimulant-use disorders are important co-morbidities of PLHIV to address as national HIV program plan to obtain epidemic control of HIV infection [38-43]. However, SUDs are not routinely screened for in HIV care and treatment settings, although highly prevalent in people who use drugs and who are seeking care. Opioid use disorders are recognized as a significant HIV risk factor for people who inject drugs and has been shown to be the largest contributor to disability-adjusted life years (DALYs) for PLHIV who use drugs $[10,37,38,44,45]$.

SUDs can be addressed in a health care setting with interventions, such as screening and brief interventions with recovery management to reduce harmful use, as well as by therapies such as cognitive-behavioral therapy (CBT)/ motivational enhancement therapy (MET), or through pharmacotherapy and medical management [46-52]. For people living with HIV with opioid dependence, treatment with medication assisted treatment (MAT) in HIV primary care improves the HIV-related outcomes of mortality, quality of life, retention in care, and antiretroviral treatment adherence [53]. WHO notes that substance-use disorders are highly prevalent, globally, and burdensome to society; but the gap between providing needed treatment and that which is locally available to reduce the burden of disease remains very wide [9]. WHO guidelines underscore the importance of HIV care settings that can provide the opportunity to screen for and manage common SUDs through a range of care and treatment options that include counseling and pharmacotherapy, i.e. MAT. The guidelines additionally urge that that these services be part of national HIV/AIDS programs, and integrated into primary care programs for PLHIV $[9,10]$.

\section{The HIV treatment cascade}

The HIV treatment cascade, also called the HIV care cascade, is an analytic tool that measures the achievement status of a HIV program in obtaining the target goals of 90/90/90. 90/90/90 refers to the targets set by the Joint United Nations Programme on HIV/AIDS (UNAIDS) by 2020: $90 \%$ of all PLHIV will know their HIV status though HIV testing; by $2020,90 \%$ of all people with diagnosed HIV infection will receive sustained antiretroviral therapy; by $2020,90 \%$ of all people receiving antiretroviral therapy will have achieved viral suppression [54].

Suppression of the HIV viral load is a surrogate marker for retention in care and medication adherence, since both are required to obtain viral load suppression. As shown in Figure 1, a standard cascade analytic tool provides a population estimate of the number of PLHIV; data comprising the number of individuals diagnosed with HIV infection, the number of PLHIV who are linked to/receiving antiretroviral treatment and the number of ART recipients obtaining a suppressed viral load. Various versions of the cascade can be generated

\section{HIV Treatment Cascade}

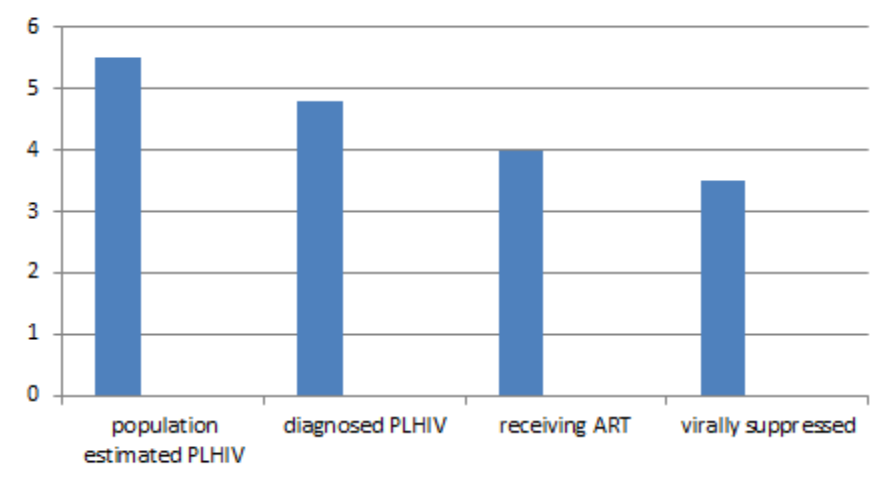

Figure 1. HIV treatment cascade

using additional components of the HIV care continuum, as well as, specific populations and subpopulations as part of the analyses of epidemic control [55,56].

An important subpopulation for analysis of epidemic control is PLHIV with CMDs and/or SUDs. A recent review has provided data on 53 national care cascades comprising $54 \%$ of the global estimate of PLHIV [57]. The data show that $48 \%$ of the global estimate of PLHIV is receiving ART and of those, $40 \%$ are virally suppressed. However, only seven countries were noted to be nearing the 90/90/90 targets, with three African countries on track to epidemic control by 2030 [58]. Thus, the treatment cascade is an excellent tool to monitor treatment outcome and quantify PLHIV who are lost to care, and for those who remain in care but do not achieve a good clinical outcome, i.e. suppressed viral load $[58,59]$. Through the analysis of the cascade, a determination can be made for the need of interventions, through the HIV care continuum, that address programmatic gaps in care and facilitate good clinical outcomes [59-61]. Analyses include the need for interventions and services that provide for the treatment of CMDs and SUDs.

\section{Services for common mental disorders and substance use disorders in HIV testing and counselling}

Using established standard survey and surveillance methodology, as well as, data reporting, an estimate for the national prevalence of PLHIV, as well as other elements of the treatment cascade can be determined [62]. The WHO has developed guidelines for HIV testing services that provides guidance, policy and recommendation for HIV testing for various settings and for differing populations [63]. National HIV programs derive their HIV testing algorithm, which varies based on available technology, from this guidance. HIV testing algorithms form the basis for an HIV diagnosis. It is estimated that globally, between 54-60\% of PLHIV have been tested and know their HIV status $[57,63]$. The common modalities for HIV testing are facility/providerbased testing, community-based testing and self-testing [63], each of which provides a setting for providing services for CMDs and SUDs. An important service that can be provided at the time of HIV testing is screening for common CMDs, such as depression and anxiety, as well as, screening for SUDs, harmful alcohol use and injection drug use [64]. One such screening in Kenya, using an acculturated, validated screening tool showed that $45 \%$ of those screened had a lifetime diagnosis of a common CMD with $15.7 \%$ an anxiety disorder, $12.3 \%$ a major depressive disorder; $11.7 \%$ a SUD, and $16.4 \%$ a life-time suicidal 
attempt [64]. At the time of screening it is also important to provide an intervention based on the screening outcome. In a community-based setting with screening performed by lay health workers or trained peers, a brief intervention comprising psychosocial support and first aid for CMDs can be provided [65]. For SUDs, a brief intervention with referral to treatment can be provided [66]. An important outcome for all tested for HIV infection is connection and access to health care. For those testing negative for HIV infection, access to social support and follow-up health care services for any CMD and SUD establishes continuity of care, and particularly important where pre-exposure prophylactics (PrEP) for the prevention of HIV infection is available [67]. For those testing positive for HIV infection, community testers could function as peer navigators/case managers to support the initiation of ART services and HIV primary care as part of same day ART/Test and Start programs $[68,69]$. For HIV testing sites located in facilities with health care providers performing the HIV testing services, navigators/case managers may also be needed based on whether all needed health care services are integrated or co-located. In this situation, the health care providers/navigators/case managers also need to be trained to provide screening and a brief intervention for common CMDs and SUDs as part of HIV testing services. Such training and service provision would also be appropriate for indexcase HIV testing as part of outreach activities [70]. Self-testing presents a challenge to provide screening and brief intervention for common CMDs and SUDs as part of HIV testing. HIV self- testing followed by facility-based care can be an option to integrate screening and brief intervention. Alternatively, home based care after self-HIV testing can incorporate screening and brief intervention for common CMDs and SUDs as part of a home-based service [71]. For either option, HIV selftesting improves access to HIV testing and reduces the anxiety related to receipt of test result [67].

\section{Services for common mental disorders and substance use disorders in initiation of antiretroviral treatment}

There are multiple barriers for PLHIV to initiate ART that result from CMDs and SUDs. These barriers occur at the family and social level, at the health care system level and at the individual level [72,73]. Family and social barriers to initiating ART include disenfranchisement, banishment, homelessness, social discrimination; health care system barriers include poor enabling environment, stigma and discrimination and lack of mental health and drug treatment; individual barriers including low self-esteem, poor health knowledge, and low motivation to initiate ART. A recent study has shown that even in the era of ART for all PLHIV, health care providers deferred ART initiation for nearly one-in three-PLHIV due to the diagnosis of a common CMD or SUD [73]. Deferral of ART results in poor HIV clinical outcomes with an increase in lost-to-follow-up, as well as, increased mortality [74]. There are interventions for health care providers and the community, such as education and social contact, that have shown short-term gains in reducing the stigma associated with CMDs, but long term solutions remain elusive [75]. Stigma and discrimination associated with CMDs and SUDs remain a formidable barrier for PLHIV to access the health care system and initiate ART. Other important interventions to promote access to and retention in ART are treatment of CMDs and SUDs [76-79]. Effective, evidencebased treatments for CMDs and SUDs provide psychosocial support and patient stability creating a recovery platform promoting good clinical outcomes for long term ART. These treatments include both psychosocial therapy and pharmacotherapy [80-83]. Integration of treatment for CMDs and SUDs into HIV care and treatment programs results in good clinical outcomes and is cost effective [76,84-87]. Thus, patients in recovery from CMDs and SUDs can initiate ART successfully, adhere to pharmacological treatment regimens and over time, achieve an undetectable viral load, thereby contributing to epidemic control of HIV infection.

\section{Services for common mental disorders and substance use disorders in alternative models of HIV services delivery}

As the international HIV treatment guidelines change over time, ART clinics have responded by developing new models of HIV services delivery to meet both guideline changes and the increasing treatment targets $[88,89]$. These new service delivery models have the ultimate goals of increased treatment capacity and sustainable quality HIV service delivery in a cost- effective manner related to the resources available. The new models go beyond the traditional clinic-based, physician centered delivery of HIV services with changes and novel interventions to personnel with task shifting, service delivery locations into the community, modifying ART clinic follow-up appointment spacing and reducing criteria that limits enrollment into ART [89-91].

Service delivery models that reduce the frequency of follow-up clinic visits and provide community-based ART prescribing and refill programs or pharmacy refill only visits, as well as, non-clinic based platforms for ART support are intended to reduce HIV clinic congestion by limiting engagement in HIV primary care for stable PLHIV with an undetectable HIV viral load [89]. These models seek to increase the quality of HIV service delivery in clinics for those PLHIV who have more medical needs. PLHIV with CMDs and SUDs often have multiple co-morbidities along with medical and social needs that require complex medical and support services for good clinical outcomes $[92,93]$. Thus, the alternative models of HIV service delivery are a positive step in addressing the needs of PLHIV with CMDs and SUDs, if the needed services for these PLHIV are accessible and available. The needed services (Table 1) are also required long-term, since CMDs and SUDs are chronic, relapsing medical conditions. Based on the need for continued engagement with the health care system, integration of services for CMDs and SUDs along the HIV treatment cascade provides for optional clinical outcomes, is cost-effective, and impacts epidemic control of HIV infection [94,95].

\section{Summary}

CMDs and SUDs occur in a higher prevalence in PLHIV than in the general population, but remain under-diagnosed and poorly treated, particularly in low and middle income countries. Services for CMDS and SUDs are important for PLHIV along the HIV treatment cascade to obtain good clinical outcomes. The HIV treatment cascade of PLHIV with CMDs and SUDs can inform national HIV programs on the impact of the services on HIV epidemic control and the need to augment services for these subpopulations to obtain epidemic control. Integration or co-location of effective evidence-based services for CMDs and SUDs into HIV primary care in the context of the new

Table 1. Services for common mental disorders and substance use disorders for people living with HIV along the HIV treatment Cascade

\begin{tabular}{|l|l|}
\hline Cascade Stage & Service for common mental disorders/Substance Use Disorder \\
\hline HIV diagnosis & $\begin{array}{l}\text { screening and brief intervention/brief therapy, MAT peer support with } \\
\text { navigation and case management suicide prevention services }\end{array}$ \\
\hline ART initiation & $\begin{array}{l}\text { screening and brief intervention/brief therapy, MAT co-located/ } \\
\text { integrated pharmacologic \& psychosocial treatment social and peer } \\
\text { group support/recovery services suicide prevention services }\end{array}$ \\
\hline Virally suppressed & $\begin{array}{l}\text { relapse prevention services, MAT social and peer group support/ } \\
\text { recovery services }\end{array}$ \\
\hline
\end{tabular}


service delivery models provide the best platform for addressing both CMDs/SUDs and HIV infection for PLHIV.

\section{Disclaimer}

The authors' views expressed in this manuscript do not necessarily reflect the views of USAID or the US Government.

\section{References}

1. World Health Organization (2013) Mental Health Action Plan 2013-2020. ISBN 978 9241506021 Geneva Switzerland. http://www.who.int/mental_health/publications/ action_plan/en/

2. American Psychiatric Association (2013) Diagnostic and Statistical Manual of Mental Disorders (DSM-5) ISBN 978-0-89042-554-1. https://www.psychiatry.org/ psychiatrists/practice/dsm

3. International Classification of Diseases and Related Health Problems (ICD-10) (2017) Mental, Behavioral and Neurodevelopmental disorders F01-F99. http://www. icd10data.com/ICD10CM/Codes/F01-F99

4. Murray CJ, Vos T, Lozano R, Naghavi M, Flaxman AD, et al. (2012) Disabilityadjusted life years (DALYs) for 291 disease and injuries in 21 regions 1990-2010: A systematic analysis for the Global Burden of Diseases Study 2010. Lancet 380: 2197 2223. [Crossref]

5. Jonsson G, Davies N, Freeman C, Joska J, Pahad S, et al. (2013) Management of menta health disorders in HIV-positive patients by the Southern African HIV Clinicians Society. S Afr J HIV Med 14. http://www.sajhivmed.org.za/index.php/hivmed/article/ view/50/70. Date accessed: 12 Apr. 2017

6. Chander G, Himelhoch S, Moore RD (2006) Substance abuse and psychiatric disorders in HIV-positive patients: epidemiology and impact on antiretroviral therapy. Drugs 66 : 769-789. [Crossref]

7. Collins PY, Holman AR, Freeman MC, Patel V (2006) What is the relevance of mental health to HIV/AIDS care and treatment programs in developing countries? A systematic review. AIDS 20: 1571-1582. [Crossref]

8. Mayston R, Kinyanda E, Chishinga N, Prince M, Patel V (2012) Mental disorders and the outcome of HIV/AIDS in low-income and middle-income countries: A systemic review. AIDS 26 (suppl. 2): S117-135. [Crossref]

9. World Health Organization (2008) mhGAP Mental Health Gap Action Programme. Scaling up care for mental, neurological and substance use disorders. ISBN: 978924 159620 6. http://www.who.int/mental health/evidence/mhGAP/en/index.html

10. World Health Organization (2009) Pharmacological treatment of mental disorders in primary health care. ISBN: 978924 1547697. http://www.who.int/mental_health/ management/psychotropic/en/index.html

11. Rabkin JG (2008) HIV and depression: 2008 review and update. Curr HIV/AIDS Rep 5: 163-171. [Crossref]

12. Unnikrishnan B, Jagannath V, Ramapuram JT, Achappa B, Madi D (2012) Study of depression and its associated factors among women living with HIV AIDS in coastal South India. ISRN AIDS 684972

13. Reis RK, Haas VJ, Santos CB, Teles SA, Galvão MT, et al. (2011) Symptoms of depression and quality of life of people living with HIV/AIDS. Rev Lat Am Enfermagem 19: 874-81.

14. Pappin M, Wouters E, Booysen F (2012) Anxiety and depression amongst patients enrolled in a public sector antiretroviral treatment programme in South Africa: A crosssectional study. BMC Public Health 12: 244. [Crossref]

15. Charles B, Jeyaseelan L, Pandian AK, Sam AE, Thenmozhi M, et al. (2012) Association between stigma, depression, and quality of life of people living with HIV/ AIDS (PLHA) in South India- A community based cross sectional study. BMC Public Health 12: 463. [Crossref]

16. Gupta R, Dandu M, Packel L, Rutherford G, Leiter K, et al. (2010) Depression and HIV in Botswana: A population-based study on gender-specific socioeconomic and behavioral correlates. PLoS One 5: e14252. [Crossref]

17. Kinyanda E, Hoskins S, Nakku J, Nawaz S, Patel V, et al. (2011) Prevalence and risk factors of major depressive disorder in HIV/AIDS as seen in semi-urban Entebbe district, Uganda. BMC Psychiatry 11: 205. [Crossref]

18. Seth P, Kidder D, Pals S, Parent J, Mbatia R, et al. (2014) Psychosocial functioning and depressive symptoms among HIV-Positive persons receiving care and treatment in Kenya, Namibia, and Tanzania. Prev Sci 15: 318-328. [Crossref]
19. Marwick KF, Kaaya SF (2010) Prevalence of depression and anxiety disorders in HIVpositive outpatients in rural Tanzania. AIDS Care 22: 415-419. [Crossref]

20. Olagunju AT, Ademeyemi JD, Ogbolu RE, Campbell EA (2012) A study on epidemiological profile of anxiety disorders among people living with HIV/AIDS in a Sub-Saharan Africa HIV clinic. AIDS Behav 16: 2192-2197. [Crossref]

21. Ofovwe CE, Ofovwe C (2013) Psychological disorders among human immunodeficiency virus-infected adults in Southern Nigeria. Afr J Reprod Health 17 (spec no 4): 177-182. [Crossref]

22. Patel V, Araya R, de Lima M, Ludermir A, Todd C (1999) Women, poverty and common mental disorders in four restructuring societies. Soc Sci Med 49: 1461-1471. [Crossref]

23. Patel V, Kleinman A (2003) Poverty and common mental disorders in developing countries. Bull World Health Organ 81: 609-615. [Crossref]

24. Stranix-Chibanda L, Chibanda D, Chingono A, Montgomery E, Wells J, et al. (2005) Screening for Psychological Morbidity in HIV-Infected and HIV-Uninfected Pregnan Women Using Community Counselors in Zimbabwe. J Int Assoc Physicians AIDS Care 4: 83-88. [Crossref]

25. Chibanda D, Mangezi W, Tshimanga M, Woelk G, Rusakaniko P, et al. (2010) Validation of the Edinburgh Postnatal Depression Scale among women in a high HIV prevalence area in urban Zimbabwe. Arch Womens Ment Health 13: 201-206. [Crossref]

26. Tesfaw G, Ayano G, Awoke T, Assefa D, Birhanu Z, et al. (2016) Prevalence and correlates of depression and anxiety among patients with HIV on-follow up at Alert Hospital, Addis Ababa, Ethiopia. BMC Psychiatry 16: 368. [Crossref]

27. Goehringer F, Bonnet F, Salmon D, Cacoub P, Paye A, et al. (2017) Causes of Death in HIV-Infected Individuals with Immunovirologic Success in a National Prospective Survey. AIDS Res Hum Retroviruses 33: 187-193

28. Bitew H, Andargie G, Tadesse A, Belete A, Fekadu W et al (2016) Suicidal Ideation, Attempt, and Determining Factors among HIV/AIDS Patients, Ethiopia. Depress Res Treat.

29. Wu YL, Yang HY, Wang J, Yao H, Zhao X, et al. (2015) Prevalence of suicidal ideation and associated factors among HIV-positive MSM in Anhui, China. Int J STD AIDS 26: 496-503.

30. World Health Organization (2014) Preventing Suicide: A global imperative. WHO Press Geneva Switzerland. http://www.who.int/mental_health/suicide-prevention/ world_report_2014/en/

31. UNAIDS. Geneva: UNAIDS (2014) The gap report. http://www.unaids.org/en/ resources/campaigns/2014/2014gapreport/gapreport.

32. Bachireddy C, Soule MC, Izenberg JM, Dvoryak S, Dumchev K, et al (2014) Integration of health services improves multiple healthcare outcomes among HIV-infected people who inject drugs in Ukraine. Drug Alcohol Depend 134: 106-14. [Crossref]

33. Tran BX, Nguyen LH, Phan HT, Latkin CA (2015) Patient Satisfaction with Methadone Maintenance Treatment in Vietnam: A Comparison of Different Integrative-Service Delivery Models. PLoS One 10: e0142644. [Crossref]

34. Kinahan JC, Surah S, Keating S, Bergin C, Mulcahy F, et al. (2016) Effect of integrating $\mathrm{HIV}$ and addiction care for non-engaging HIV-infected opiate-dependent patients. Ir J Med Sci 185: 623-8. [Crossref]

35. Vu NT, Maher L, Zablotska I (2015) Amphetamine-type stimulants and HIV infection among men who have sex with men: implications on HIV research and prevention from a systematic review and meta-analysis. J Int AIDS Soc 18: 19273. [Crossref]

36. Vagenas P, Azbel L, Polonsky M, Kerimi N, Mamyrov M, et al. (2013) A Review of Medical and Substance Use Co-Morbidities in Central Asian Prisons: Implications for HIV Prevention and Treatment. Drug Alcohol Depend 132 Suppl 1: S25-31. [Crossref]

37. Degenhardt L, Whiteford HA, Ferrari AJ, Baxter AJ, Charlson FJ, et al. (2013) Global burden of disease attributable to illicit drug use and dependence: Findings from the Global Burden of Disease Study 2010. Lancet 382: 1564-74. [Crossref]

38. Vagenas P, Azar MM, Copenhaver MM, Springer SA, Molina PE, et al. (2015) The Impact of Alcohol Use and Related Disorders on the HIV Continuum of Care: a Systematic Review: Alcohol and the HIV Continuum of Care. Curr HIV/AIDS Rep 12: 421-436. [Crossref]

39. Meade CS, Towe SL, Watt MH, et al. (2015) Addiction and treatment experience among active methamphetamine users recruited from a township community in Cape Town, South Africa: A mixed-methods study. Drug Alcohol Depend 152: 79-86. [Crossref] 
40. Zhang XD, Kelly-Hanku A, Chai JJ, Luo J, Temmerman, et al. (2015) Sexual and reproductive health risks amongst female adolescents who use amphetamine-type stimulants and sell sex: a qualitative inquiry in Yunnan, China. Harm Reduct $J$ 12: 34.

41. Beyrer C, Razak MH, Jittiwutikarn J, Suriyanon V, Vongchak T, et al. (2004) Methamphetamine users in northern Thailand: changing demographics and risks for HIV and STD among treatment-seeking substance abusers. Int J STD AIDS 15: 697704. [Crossref]

42. Kresina TF, Condor LD, Lapidos-Salaiz IF (2016) The Impact of Screening, Diagnosis and Management of Substance Use and Addictive Disorders In HIV Care in Low and Middle Income Countries. Res HIV Retroviral Infect 1: 1-10. http://crescopublications. org/pdf/RHRIOA/RHRIOA-1-003.pdf

43. Kresina TF, Conder LD, Lapidos-Salaiz IF (2016) The Impact of Screening, Diagnosis and Management of Alcohol Use Disorders In HIV Care in Low and Middle Income Countries. Ann Pub Health Res 3: 1035. https://www.jscimedcentral.com/PublicHealth/ publichealth-3-1035.pdf

44. World Health Organization (2014) Consolidated Guidelines on HIV prevention, diagnosis, treatment and care for key populations. WHO Press, Geneva, Switzerland.14 ISBN 978924150743 1. http://www.who.int/hiv/pub/guidelines/keypopulations/en/

45. World Health Organization (2006) Basic Principles for Treatment and Psychosocial Support of Drug Dependent People Living with HIV/AIDS 2006. http://www.who.int/ substance_abuse/publications/basic_principles_drug_hiv.pdf.

46. Schaub MP, Wenger A, Berg O, Beck T, Stark L, et al. (2015) A Web-Based SelfHelp Intervention With and Without Chat Counseling to Reduce Cannabis Use in Problematic Cannabis Users: Three-Arm Randomized Controlled Trial. J Med Internet Res 17: e232. [crossref]

47. Fornili KS (2016) Part 2: Screening, Brief Intervention and Referral to Treatment Plus Recovery Management: A Proposed Model for Recovery-Oriented Primary Care. $J$ Addict Nurs 27: 86-93. [Crossref]

48. Vujanovic AA, Meyer TD, Heads AM, Stotts AL, Villarreal YR, et al. (2016) Cognitive-behavioral therapies for depression and substance use disorders: an overview of traditional, third-wave, and transdiagnostic approaches. Am J Drug Alcohol Abuse 5: 1-14. [Crossref]

49. Davis DR, Kurti AN, Skelly JM, Redner R, White TJ, et al. (2016). A review of the literature on contingency management in the treatment of substance use disorders, 2009-2014. Prev Med Aug 8. pii: S0091-7435(16)30214-6.

50. Drapkin ML, Wilbourne P, Manuel JK, Baer J, Karlin B, et al. (2016) National Dissemination of Motivation Enhancement Therapy in the Veterans Health Administration: Training Program Design and Initial Outcomes. J Subst Abuse Treat 65: 83-7. [Crossref]

51. Connery HS (2015) Medication-assisted treatment of opioid use disorder: review of the evidence and future directions. Harv Rev Psychiatry 23: 63-75. [Crossref]

52. Lee J, Kresina TF, Campopiano M, Lubran R, Clark HW (2015) Use of pharmacotherapies in the treatment of alcohol use disorders and opioid dependence in primary care. Biomed Res Int 2015: 137020. [Crossref]

53. Batkis MF, Treisman GJ, Angelino AF (2010) Integrated opioid use disorder and HIV treatment: rationale, clinical guidelines for addiction treatment, and review of interactions of antiretroviral agents and opioid agonist therapies. AIDS Patient Care STDS 24: 15-22. [Crossref]

54. Joint United Nations Programme on HIV/AIDS (UNAIDS) (2014) 90-90-90 An ambitious treatment target to help end the AIDS epidemic. UNAIDS / JC2684. http:// www.unaids.org/sites/default/files/media_asset/90-90-90_en_0.pdf

55. McFall AM, Mehta SH, Srikrishnan AK, Lucas GM, Vasudevan CK, et al. (2016) Getting to 90: linkage to HIV care among men who have sex with men and people who inject drugs in India. AIDS Care 28: 1230-1239. [Crossref]

56. AL Wirtz, CE Zelaya, C Latkin, A Peryshkina, N Galai, et al. (2016) The HIV care continuum among men who have sex with men in Moscow, Russia: a cross-sectional study of infection awareness and engagement in care. Sex Transm Infect 92: 161-167. [Crossref]

57. Granich R, Gupta S, Hall I, Aberle-Grasse J, Hader S, et al. (2017) Status and methodology of publicly available national HIV care continua and 90-90-90 targets: A systematic review. PLoS Med 14: e1002253. [Crossref]

58. Cohen J (2016) AIDS epidemic nears control in three African countries. Science 354: 1213. [Crossref]

59. Low-Beer D, Beusenberg M, Hayashi C, Calleja T, Marsh K, et al. (2017) Monitoring HIV Treatment and the Health Sector Cascade: From Treatment Numbers to Impact. AIDS Behav. [Crossref]
60. Genberg BL, Shangani S, Sabatino K, Rachlis B, Wachira J et al. (2016) Improving engagement in the HIV care cascade: A systematic review of interventions involving People living with HIV/AIDS as peers. AIDS Behav 20: 2452-2463. [Crossref]

61. Church K, Machiyama K, Todd J, Njamwea B, Mwangome M, et al. (2017) Identifying gaps in HIV service delivery across the diagnosis-to-treatment cascade: findings from health facility surveys in six sub-Saharan countries. J Int AIDS Soc 20: 1-14. [Crossref]

62. Kim AA, Mukui I, N'gan'ga L, Katana A, Koros D, et al. (2016) Progress in Reversing the HIV Epidemic through Intensified Access to Antiretroviral Therapy: Results from a Nationally Representative Population-Based Survey in Kenya, 2012. PLoS One 11: e0148068. [Crossref]

63. WorldHealthOrganization(WHO)(2015)ConsolidatedguidelinesonHIV testingservices WHO Press. http://apps.who.int/iris/bitstream/10665/179870/1/9789241508926_eng. pdf?ua $=1 \& u a=1$

64. Kwobah E, Epstein S, Mwangi A, Litzelman D, et al. (2017) PREVALENCE of psychiatric morbidity in a community sample in Western Kenya. BMC Psychiatry 17: 30. [Crossref]

65. Sagar R, Prakash S (2016) Dignity \& first aid in mental health. Indian J Med Res 144: 496-498. [Crossref]

66. Bray JW, Del Boca FK, McRee BG, Hayashi SW, Babor TF (2017) Screening, Brief Intervention and Referral to Treatment (SBIRT): rationale, program overview and cross-site evaluation. Addiction 112 Suppl 2: 3-11. [Crossref]

67. Ngure K, Heffron R, Mugo N, et al. (2017) Feasibility and acceptability of HIV selftesting among pre-exposure prophylaxis users in Kenya. $J$ Int AIDS Soc 20: 1-8. [Crossref]

68. Kalua T, Tippett Barr BA, van Oosterhout JJ, Mbori-Ngacha D, Schouten EJ, et al (2017) Lessons Learned From Option B+ in the Evolution Toward "Test and Start" From Malawi, Cameroon, and the United Republic of Tanzania. J Acquir Immune Defic Syndr 75 Suppl 1: S43-S50. [Crossref]

69. Kresina TF, Kaplowitz L, Ahadpour M, Johnson K (2016) Test and Start for People Living with HIV and Who Use Drugs in Low and Middle Income Countries. HIV/ AIDS Res Treat 3: 15-21

70. Kahabuka C, Plotkin M, Christensen A, Brown C, Njozi M, et al. (2017) Addressing the First 90: A Highly Effective Partner Notification Approach Reaches Previously Undiagnosed Sexual Partners in Tanzania. AIDS Behav. [Crossref]

71. MacPherson P, Lalloo DG, Webb EL, Maheswaran H, Choko AT, et al. (2014) Effect of optional home initiation of HIV care following HIV self-testing on antiretroviral therapy initiation among adults in Malawi: a randomized clinical trial. JAMA 312: 372 379. [Crossref]

72. Chakrapani V, Velayudham J, Shunmugam M, Newman PA, Dubrow R (2014) Barriers to antiretroviral treatment access for injecting drug users living with HIV in Chennai, South India. AIDS Care 26: 835-41. [Crossref]

73. Weiser J, Brooks JT, Skarbinski J, West BT, Duke CC, et al. (2017) Barriers to Universal Prescribing of Antiretroviral Therapy by HIV Care Providers in the United States, 2013-2014. J Acquir Immune Defic Syndr 74: 479-487. [Crossref]

74. Su S, Li S, Li S, Gao L, Cai Y, et al. (2016) Gaps in the Continuum of HIV Care Long Pretreatment Waiting Time between HIV Diagnosis and Antiretroviral Therapy Initiation Leads to Poor Treatment Adherence and Outcomes. Biomed Res Int 2016: 2648923. [Crossref]

75. Thornicroft G, Mehta N, Clement S, Evans-Lacko S, Doherty M, et al. (2016) Evidence for effective interventions to reduce mental-health-related stigma and discrimination. Lancet 387(10023): 1123-32.

76. Kresina TF, Condor LD, Lapidos-Salaiz IF (2016) The Impact of Screening, Diagnosis and Management of Substance Use and Addictive Disorders In HIV Care in Low and Middle Income Countries. Res HIV Retroviral Infect 1;1:1-10. http:/ crescopublications.org/pdf/rhrioa/RHRIOA-1-003.pdf

77. Kresina TF, Conder LD, Lapidos-Salaiz IF (2016) The Impact of Screening, Diagnosis and Management of Alcohol Use Disorders In HIV Care in Low and Middle Income Countries. Ann Pub Health Res 3: 1035.

78. Chibanda D, Cowan FM, Healy JL, Abas M, Lund C (2015) Psychological interventions for Common Mental Disorders for People Living With HIV in Low- and MiddleIncome Countries: systematic review. Trop Med Int Health 20: 830-9. [Crossref]

79. Chibanda D, Weiss HA, Verhey R, Simms V, Munjoma R, et al. (2016) Effect of a Primary Care-Based Psychological Intervention on Symptoms of Common Mental Disorders in Zimbabwe: A Randomized Clinical Trial. JAMA 316: 2618-2626. [Crossref] 
80. Himelhoch S, Medoff DR (2005) Efficacy of antidepressant medication among HIVpositive individuals with depression: a systematic review and meta-analysis. AIDS Patient Care STDS 19: 813-822. [Crossref]

81. Himelhoch S, Medoff DR, Oyeniyi G (2007) Efficacy of group psychotherapy to reduce depressive symptoms among HIV-infected individuals: a systematic review and metaanalysis. AIDS Patient Care STDS 21:732-739. [Crossref]

82. Mlunde LB, Sunguya BF, Mbwambo JK, Ubuguyu OS, Yasuoka J et al. (2016) Association of opioid agonist therapy with the initiation of antiretroviral therapy - a systematic review. Int J Infect Dis 46: 27-33. [Crossref]

83. Papas RK, Sidle JE, Gakinya BN, Baliddawa JB, Martino S, et al. (2011) Treatment outcomes of a stage 1 cognitive-behavioral trial to reduce alcohol use among human immunodeficiency virus-infected out-patients in western Kenya. Addiction 106: 21562166. [Crossref]

84. Adams JL, Gaynes BN, McGuinness T, Modi R, Willig J, et al. (2012) Treating depression within the HIV "medical home": a guided algorithm for antidepressant management by HIV clinicians. AIDS Patient Care STDS 26: 647-654. [Crossref]

85. Pyne JM1, Fortney JC, Curran GM, Tripathi S, Atkinson JH, et al. (2011) Effectiveness of collaborative care for depression in human immunodeficiency virus clinics. Arch Intern Med 171: 23-31. [Crossref]

86. Hyle EP, Naidoo K, Su AE, El-Sadr WM, Freedberg KA (2014) HIV, tuberculosis, and noncommunicable diseases: what is known about the costs, effects, and costeffectiveness of integrated care? J. Acquir. Immune Defic. Syndr 67(Suppl. 1): S87S95. [Crossref]
87. Galárraga O, Gao B, Gakinya BN, Klein DA, et al. (2017) Task-shifting alcohol interventions for HIV+ persons in Kenya: a cost-benefit analysis. BMC Health Serv Res 17: 239. [Crossref]

88. World Health Organization (WHO). Guidelines: HIV- http://www.who.int/hiv/pub/ guidelines/en/

89. Zakumumpa H, Bennett S, Ssengooba F (2017) Modifications to ART service delivery models by health facilities in Uganda in promotion of intervention sustainability: a mixed methods study. Implement Sci 12: 45. [Crossref]

90. Schneider H, Blaauw D, Gilson L, Chabikuli N, Goudge J (2006) Health systems and access to antiretroviral drugs for HIV in Southern Africa: service delivery and human resources challenges. Reprod Health Matters 14: 12-23. [Crossref]

91. Callaghan M1, Ford N, Schneider H (2010) A systematic review of task- shifting for HIV treatment and care in Africa. Hum Resour Health 8: 8. [Crossref]

92. Bruce RD1, Kresina TF, McCance-Katz EF (2010) Medication-assisted treatment and HIV/AIDS: aspects in treating HIV-infected drug users. AIDS 24: 331-340. [Crossref]

93. Mayston R, Kinyanda E, Chishinga N, Prince M, Patel V (2012) Mental disorder and the outcome of HIV/AIDS in low-income and middle-income countries: a systematic review. AIDS 26 Suppl 2: S117-35. [Crossref]

94. Guise A, Seguin M, Mburu G, McLean S, Grenfell P, et al. (2017) Integrated opioid substitution therapy and HIV care: a qualitative systematic review and synthesis of client and provider experiences. AIDS Care 10: 1-10. [Crossref]

95. Hanlon C, Luitel NP, Kathree T, Murhar V, Shrivasta S (2014) Challenges and opportunities for implementing integrated mental health care: a district level situation analysis from five low- and middle-income countries. PLoS One 9: e88437. [Crossref]

Copyright: $\odot 2017$ Kresina TF. This is an open-access article distributed under the terms of the Creative Commons Attribution License, which permits unrestricted use, distribution, and reproduction in any medium, provided the original author and source are credited. 